\title{
Pobreza y celebridades del espectáculo: un debate del accionar internacional ${ }^{*}$
}

\section{Erli Margarita Marín Aranguren** Nedi Natalia Millares Abella***}

Este artículo muestra la incidencia de las celebridades del espectáculo, como agentes de la sociedad civil, para transformar la pobreza que se vive en el mundo, especialmente en los países del cuerno de África. Ellas juegan un rol protagónico en términos de sensibilización de la situación. Buscan que sus audiencias pasen a la acción. Si bien no es una estrategia de acción nueva, en este artículo se hace un recuento de cinco hitos globales, donde las campañas han tenido como reeditores sociales a estrellas del espectáculo que han trabajo de la mano con otras organizaciones de la sociedad civil o redes transnacionales. Para evidenciar el accionar de estos agentes, primero se abordan los referentes teóricos que acercarán al lector a la discusión planteada. Posteriormente, se hace un recuento lineal de las interacciones de las celebridades del espectáculo con las acciones de la lucha contra la pobreza, las cuales no solo han generado un cambio en las campañas, sino también en la narrativa del tema. Esto demuestra la eficacia para incidir en decisiones políticas que han posibilitado la reducción de

* Si bien el mundo del espectáculo es amplio y abarca casi todas las modalidades artísticas, en este caso se hará referencia a quienes pertenecen a la esfera musical comercial.

** MA Relaciones Internacionales. Profesora titular, Facultad de Finanzas, Gobierno y Relaciones Internacionales. Investigadora en el Centro de Investigaciones y Proyectos Especiales - CIPE, Universidad Externado de Colombia, Bogotá (Colombia). [erli.marin@uexternado.edu.co].

*** Estudiante de IX semestre de Gobierno y Relaciones Internacionales, Universidad Externado de Colombia, Bogotá (Colombia). [nedi.millares@est.uexternado.edu.co].

Recibido: 17 de febrero de 2017 / Modificado: 3 de agosto de 2017 / Aceptado: 10 de agosto de 2017

Para citar este artículo:

Marín Aranguren, E. M. y Millares Abella, N. N. (2017). Pobreza y celebridades del espectáculo: un debate del accionar internacional. OAsIs, 26, 41-60.

DOI: https://doi.org/10.18601/16577558.n26.04 
la pobreza, debido a que el cambio de narrativa ha permitido la vinculación de líderes políticos y de organizaciones internacionales. Finalmente, se presentan las conclusiones, las cuales no solo abordan lo positivo de este aporte, sino también aspectos como el mercado de la beneficencia, la superficialidad de la información que se genera y que no logra concientizar, y la doble moral del accionar de los Estados.

Palabras clave: celebridades, fundraising, organizaciones de la sociedad civil, mercado de la beneficencia, filantropía.

\section{Poverty and celebrities: A debate of their international action}

\section{ABSTRACT}

This article aims to show the impact of celebrities as agents of civil society, and how they can transform poverty in the world, especially in the countries from the Horn of Africa. These celebrities play a leading role in sensitizing the public in general to the situation, and in leading their audiences to action. While this is not a new action strategy, this article examines five global milestones where campaigns have used celebrities as social re-editors. They are principal agents in civil society organizations in which they are involved, and / or transnational networks. In order to demonstrate the actions of these agents, we will first address the theoretical references that will bring the reader into the discussion. Then, there will be a linear review of the celebrities' interactions with activities in fighting poverty, which not only have generated changes in the campaigns, but also in the subject narratives. This demonstrates the effectiveness in influencing political decisions which have made poverty reduction possible. These changes in narratives have allowed the participation of political leaders and international organizations. Finally, the conclusions regarding the debate discussed will be presented, which will not only address the positive aspects of this contribution, but will also look at aspects such as marketing for charity, the superficiality of the information they provide, which raises awareness without consciousness and the double moral applied by the States in their actions.

Key words: Celebrities, fundraising, civil society organizations, marketing for charity, philanthropy.

Desde mediados del siglo pasado puede advertirse que la humanidad tiene puestos sus ojos en la erradicación de la pobreza. Inicialmente, fueron las religiones las que hicieron reflexionar sobre las dimensiones de la pobreza en el mundo. Un poco más tarde, los estudios de académicos de organismos multilaterales revelaron cifras que alarmaron a la humanidad. Los Estados fortalecieron los programas para mejorar el Estado de bienestar y los debates comenzaron ${ }^{1}$. Al ser un problema global, no solo este agente internacional fue llamado a

1 Ampliar en Brady (2005), quien hace un recuento histórico de la relación del Estado de bienestar y la pobreza de 1967 a 1997. 
proveer soluciones. El sistema internacional de cooperación se enfiló para trabajar en la superación de la pobreza, de la mano con los abordajes para lograr el desarrollo². Un paso que ha hecho historia lo dieron las celebridades del espectáculo, de la mano de organizaciones de la sociedad civil, aspecto que se quiere subrayar en este artículo.

En realidad, la pobreza puede ser vista desde diferentes ángulos. El nobel de economía, Amartya Sen ${ }^{3}$, concibe la pobreza como:

...la privación de capacidades básicas y no meramente como la falta de ingresos, que es el criterio habitual con el que se identifica la pobreza. La perspectiva de la pobreza basada en las capacidades no entrańa el rechazo de la razonable idea de que la falta de renta es una de las principales causas de las pobreza, ya que la falta de renta puede ser una im- portante razón por la que una persona está privada de capacidades (1999, p. 114).

De hecho, en el mundo se habla de pobreza y de pobreza extrema. Ambas han sido objeto de atención por parte de los organismos multilaterales como el Banco Mundial, institución que ha dedicado esfuerzos para cuantificarla y medir los impactos tanto de su existencia como de las políticas para erradicarla. El Banco cuenta con indicadores internacionales para una $y$ otra. No obstante, ha de tenerse presente que no son fijos, son multidimensionales y se actualizan en contexto. En la tabla 1 se muestra la variación del monto del estándar internacional mínimo de pobreza. Sin embargo, la misma Comisión Económica para América Latina y el Caribe (CEPAL) insta a la utilización de líneas nacionales, para mayores precisiones.

Tabla 1

Variación del monto del estándar internacional mínimo de pobreza

\begin{tabular}{|l|c|c|c|c|}
\hline Año & 1991 & 2000 & 2005 & 2011 \\
\hline Indicador & US\$1 & US $\$ 1,08$ & US $\$ 1,25^{*}$ & US\$1,90 \\
\hline
\end{tabular}

* La meta de reducción de la proporción de pobres, teniendo en cuenta este monto diario, se cumplió a nivel global en el 2010. Quedaron pendientes algunos países en África Subsahariana (Domínguez, 2014, p. 8).

Fuente: CEPAL (2010, p. 48).

2 Aquí no se ahondará sobre esta discusión, más bien se remite a Domínguez (2014), quien hace un recuento del proceso desde la perspectiva de la cooperación internacional. También se invita a revisar el llamado de Sen, quien considera que "el desarrollo puede concebirse como un proceso de expansión de las libertades reales que disfrutan los individuos" (1999, p. 19).

3 El enfoque de la pobreza basado en capacidades considera: 1) la pobreza puede identificarse de forma razonable con la privación de capacidades; el enfoque centra la atención en las privaciones que son intrínsecamente importantes (a diferencia de la renta baja que solo es instrumentalmente importante); 2) hay otros factores que influyen en la 
Está visto que no se puede focalizar en grupos poblacionales precisos como campesinos, indígenas o afros. Tampoco es posible mirar la pobreza desde una sola dimensión, por eso se han creado diferentes indicadores. Desde finales del siglo pasado se sabe que cuando se habla de pobreza es limitado referirse a esta únicamente en términos monetarios; por esta razón, desde el 2010 se estableció el índice de pobreza multidimensional (IPM) ${ }^{4}$.

Si bien la humanidad viene trabajando para erradicar la pobreza y la pobreza extrema, al punto de establecerla en los Objetivos de Desarrollo del Milenio 5 , con metas precisas, las cifras son aún aterradoras ${ }^{6}$. En la tabla 2 se señala la tasa de incidencia de la pobreza, en 7 hitos importantes, en los últimos 35 años.

Tabla 2

Tasa de incidencia de la pobreza sobre la base de US\$1,90 por día

\begin{tabular}{|c|c|}
\hline Año & Porcentaje de la población \\
\hline 1981 & 42,15 \\
\hline 1984 & 39,6 \\
\hline 1987 & 34,81 \\
\hline
\end{tabular}

\begin{tabular}{|c|c|}
\hline 1993 & 33,49 \\
\hline 2002 & 25,3 \\
\hline 2005 & 20,37 \\
\hline 2011 & 13,5 \\
\hline
\end{tabular}

Fuente: Banco Mundial (2013).

Estas cifras fueron las que, a final del siglo pasado, alertaron a las celebridades, quienes decidieron tomar acción. Para involucrar a más gente emprendieron campañas alrededor del mundo. Si bien es un repertorio de acción que mueve multitudes, los debates acerca de estas acciones de las celebridades del espectáculo frente a la pobreza no se hicieron esperar. En este artículo se busca examinar su modo de operar, ¿cuál ha sido su rol en la erradicación de la pobreza? Y ¿qué actividades han sido las de mayores dimensiones? En uno y otro caso, los debates rondan su accionar, más cuando -si bien ha disminuido- el problema persiste en el mundo. Aun así, los repertorios de acción desarrollados por ellos son destacados debido a su incidencia en el diseño de políticas a nivel internacional para atacar el problema del hambre y la pobreza en países del tercer mundo.

Para abordar el tema propuesto, en un primer momento se establecen algunos referentes

privación de capacidades -y, por tanto, en la pobreza real además de la renta (la renta no es el único instrumento que genera capacidades); 3) la relación instrumental entre la falta de renta y la falta de capacidades varía de unas comunidades a otras e incluso de unas familias a otras y de unos individuos a otros (Sen, 1999, p. 114).

4 Para ampliar, ver Policy - A multidimensional approach. Recuperado de http://www.ophi.org.uk/policy/multidimensional-poverty-index/

5 No debe olvidarse que la narrativa de estos objetivos, precisamente, estuvo dominada por la pobreza.

6 Hoy las narrativas son de desigualdad y sostenibilidad, que son concomitantes a la pobreza. 
teóricos. En un segundo momento, se hace un recorrido histórico por los hitos marcados por las celebridades, de la mano de un análisis sobre cada una de las iniciativas emprendidas por ellos. Finalmente, se concentra un apartado de comentarios, a manera de conclusión, que señalan cómo su accionar sirvió para concientizar sobre la importancia de tomar medidas en aras de erradicar la pobreza. Ellos, como líderes de la sociedad civil, son vehículos vitales en la transformación y configuración de las narrativas que han dado pie para consolidar el nuevo discurso, que implica nuevas dimensiones para entender un problema que aún requiere soluciones.

\section{ALGUNOS REFERENTES TEÓRICOS}

Si bien en la introducción apenas se nombran conceptos de gran contenido como pobreza y desarrollo, se invita a los lectores a revisar otros artículos de este dosier para ahondar en ello. No obstante, los referentes teóricos que posibilitan focalizar la discusión son cuatro: organizaciones de la sociedad civil global o, como algunos autores las denominan, redes transnacionales de defensa; narrativas, repertorios de acción (donde cabe destacar el rol de reeditores sociales) y campañas. Es relevante anotar que -como líderes- las celebridades hacen parte de las organizaciones de la sociedad civil global/internacional ${ }^{7}$ o redes transnacionales de defensa, pues como señala Marc Langevin, "tienen un rol determinante en la conformación de las redes que participen en la transformación de los intereses privados en política pública” (Massal, 2007, p. 61).

En realidad, las celebridades o estrellas de la música -en este caso del espectáculo artístico- son componente de la sociedad civil internacional, $\mathrm{y}$, al mismo tiempo, son agentes, en tanto aglutinadoras de voluntades. Las celebridades pueden ser reeditoras sociales cuando toman las causas del sentir de la ciudadanía y usan su reconocimiento mundial para ejercer liderazgo social en torno a un asunto glocal -en este caso, la pobreza-, de manera tal que, puede decirse, desarrollan tanto la política de información como la política de apoyo que señalan Keck y Sikkink (2000) en tanto modos

\footnotetext{
Massal (2007) recuerda que algunos autores anotan diferencias conceptuales en los dos términos; por ejemplo, algunos conciben la sociedad internacional ya no conformada solo por los Estados, sino como una sociedad donde se difunde una cultura mundial donde los vehículos son organizaciones globales que pueden ser no gubernamentales. De hecho, hay una división en la literatura anglosajona y europea sobre el concepto mismo de sociedad civil internacional. Los anglosajones la admiten como un hecho innegable e ineludible, pero los europeos son escépticos, como es el caso de Pouligny, quien se enfoca en el modo de articulación de procesos de movilización. No obstante, aquí se hace referencia a las Redes Transnacionales de Defensa, de Keck y Sikkink (2000), y se toman como sinónimos, por los alcances de las campañas. De hecho, al acuñar el término de Keck y Sikkink se retoman esas estructuras comunicativas y movilizadoras señalas por ellas, que son las que logran incidir en la agenda de política pública, situación que en este artículo se quiere señalar.
} 
de acción propios de las redes transnacionales. De un lado, son promotoras de información para crear conciencia, no porque la construyan ellos mismos, sino porque se convierten en vehículos para que la ciudadanía tenga data de manera concisa, precisa y sencilla. Del otro lado, porque apelan al reconocimiento de ser celebridad para involucrar a otros actores o líderes, a fin de hacerlos miembros activos de una causa. De esta manera, logran concientizar o sensibilizar a más gente para una causa. Las estrellas del espectáculo, más que ser profundas conocedoras del problema, lideran estrategias de concientización para buscar un cambio de comportamiento en la gente.

Uno de los aportes fundamentales de las estrellas del espectáculo como agentes de la sociedad civil es el hecho de que, por medio de sus iniciativas para concientizar sobre el problema de la pobreza, logran desarrollar un lenguaje dinámico que cambia la narrativa. $\mathrm{Al}$ tener un cambio de narrativa, el discurso oficial de diversos agentes varía y surgen transformaciones, que en este caso pueden llegar a cambiar la realidad de los países afectados por hambrunas y pobreza. El cambio de narrativa transformado por las celebridades del espectáculo genera un mensaje positivo frente a la problemática, de manera que las acciones he- chas por estos agentes llegan a ser consideradas como efectivas.

Como señala Marshall Ganz (2011),

La narrativa es un medio discursivo que permite acceder a los valores que nos llenan de coraje para tomar decisiones en condiciones de incertidumbre, de ejercer la agencia. [...] Es a través de esta experiencia compartida de nuestros valores, que podemos comprometernos con los demás, motivando a los otros a la acción; y así encontrar el coraje para tomar riesgos, explorar posibilidades y encarar los desafíos que se deben enfrentar. La narrativa pública, entendida como un arte de liderazgo, es un recurso invaluable que nos aparta de la apatía, la alienación, el cinismo y el derrotismo ${ }^{8}$ (traducción propia).

Las acciones de las celebridades del espectáculo no son inadvertidas para los medios de comunicación. Esto permite que problemáticas como la pobreza entren a la agenda de los gobiernos y se ejecuten acciones que la limiten y, al final, la eliminen. Lo cierto es que los repertorios de acción de las celebridades del espectáculo atraen, cada vez más, a individuos con un interés común. Su papel en la lucha contra la pobreza no es fortuito. Por el poder que poseen para generar opinión y su convicción en la posibilidad de transformar las situaciones de pobreza asumen el rol y logran

\footnotetext{
8 "Narrative is the discursive means we use to access values that equip us with the courage to make choices under conditions of uncertainty, to exercise agency [...] It is through the shared experience of our values that we can engaged with others; motivate one another to act; and find the courage to take risks, explore possibility, and face the challenges we must face. Public narrative, understood as a leadership art, is thus an invaluable resource to stem the tides of apathy, alienation, cynicism and defeatism”.
} 
ser más escuchados por los reproductores de información y los tomadores de decisiones, dada su legitimidad cultural y social, su credibilidad y la visibilidad de su accionar. Luego, se convierten en reeditores sociales (Marín, 2009). La evolución de su rol como agentes de la sociedad civil ha hecho que organizaciones como el Centro para la Innovación de la Gobernanza Internacional (CIGI) haya propuesto el término de diplomacia de las celebridades, debido a su incidencia en cumbres internacionales donde participan diferentes países, como se evidenciará más adelante con una serie de hitos/casos estudiados.

Estas celebridades, como agentes, han actuado en el marco de la lucha contra la pobreza. Primero, son promotores de información, la dinamizan. Son portadores de data digerible y eso es lo que los lleva a ser parte integral de esas estructuras comunicativas y movilizadoras que trabajan, mancomunadamente, con los medios de comunicación ${ }^{9}$. En muchos casos, se cuenta con estrategias de comunicación y de marketing asociativo ${ }^{10}$, para mejorar la competitividad en la búsqueda de nuevos recursos. Este accionar puede ser visto al menos desde dos aristas contrapuestas. De un lado, de manera positiva, como lo resaltan Sampedro, Jerez y Novara (2002, pp. 251-285), con solidaridad, equidad y justicia, para lograr legitimidad y ayuda ciudadana. Del otro lado, de manera negativa, desde lo que se conoce como el mercado de la beneficencia ${ }^{11}$. Como quiera que sea las celebridades, si bien comunican mensajes, en este caso para erradicar la pobreza, son gestoras de recursos.

De hecho, en este sentido, los artistas del espectáculo también refuerzan la "comunicación para el desarrollo"12, en la que se puede ubicar el marketing social, una corriente que trabaja con estrategias de campaña en las que la población es el objetivo, y donde los beneficiarios deben cambiar de comportamiento, partiendo del supuesto de que las prácticas comunes son erróneas (Gumucio, 2004, p. 10).

Con estas claridades conceptuales, ahora se procederá a la presentación de cinco casos puntuales, donde las celebridades del mundo del espectáculo han logrado sensibilizar a la sociedad en torno a la erradicación de la pobreza. La dinámica de las campañas que aquí se consideran como hito impide seguir un orden cronológico en estricto sentido; sin embargo, se mantiene una lógica contextual

9 Trabajo que se hace especialmente con los medios de comunicación internacionales de mass media (radio, televisión y prensa escrita).

10 Conjunto de instrumentos que posibilita a las organizaciones presentar causas a la sociedad, para que esta adopte un compromiso financiero.

11 La solidaridad, como parte de la cooperación para el desarrollo, se ha insertado en lo que se conoce como mercado de la beneficencia o del dolor; expresiones sinónimas de mercado de la caridad, que introdujo el fundador francés de Médicos sin Fronteras, B. Kouchner.

12 Esta tiene como objetivo principios como el diálogo y el debate. 
con la que se permite explicar el repertorio, el trabajo del reeditor, la incidencia y la interacción alcanzada. Cabe anotar que la búsqueda de la información de este tipo de campañas se realizó retomando lo sucedido en los últimos 30 años, desde 1985. Por tal motivo este artículo, más que inclinarse por alguna de las posiciones que marcan el debate, lo que busca es mostrar que las celebridades, como componentes de la sociedad civil, trabajan en alianza o en red con otros componentes, y logran incidencias en los asuntos internacionales (la pobreza en este caso). Además, son inspiradoras para otra serie de temas de agenda internacional que requirieron de campañas internacionales de concientización y recaudación de fondos, para abordar algunas de las crisis humanitarias del mundo.

Para esa la época de los sesenta, los debates sobre la capacidad de la industria de la música y el espectáculo para abordar las problemáticas coyunturales coparon los escenarios académicos. Cabe puntualizar que al análisis de la canción protesta se le puede dar inicio en esa década, cuando acontecen en el mundo dos sucesos importantes; primero, el movimiento por los derechos civiles en Estados Unidos liderado por Martin Luther King; segundo, el movimiento que estaba en contra de la guerra en Vietnam (Richey y Ponte, 2008, p. 716). Después, en la siguiente década, reaparece la canción protesta para motivar el activismo en los temas globales (viH/sida, terremoto en México, tuberculosis, malaria, tsunami en el

\footnotetext{
13 Que se realizó en julio de 1985 en Montreal, Canadá.

14 MySpace, por ejemplo.
}

océano Índico, entre otras). Al punto que autores como Andrew Cooper (2008, p. 3) llegan a mencionar la "bonoización de la diplomacia".

De manera que en la III Conferencia Internacional de la Asociación Internacional de Estudios de la Música Popular ${ }^{13}$, la discusión central se dio en torno a la posibilidad de que el rock and roll fuera un medio de expresión popular para mostrar el inconformismo y la opción para rebelarse sobre las situaciones de extrema pobreza que se vivían en África. De hecho, Ullestad (1987, p. 70) considera que el rock and roll es, en sí mismo, un claro ejemplo de la canción protesta, desde la cultura popular. En efecto, a comienzos de la década de los setenta, la canción Imagine, de Jonh Lennon, se convierte en una muestra de ello.

Por la misma época, los medios de comunicación empiezan a consolidarse como el cuarto poder en el mundo. Por el periodo en que las estrellas del espectáculo comienzan a realizar diferentes repertorios de acción, nacen las redes sociales ${ }^{14}$. De manera precisa, internet posibilita el desarrollo de páginas web. En el 2000 estalla la burbuja del internet revolucionando la manera en que accedemos a la información. Finalmente, en el 2004 y el 2006, con la aparición de Facebook y Twitter, las redes sociales cobran gran importancia, haciendo que los medios tradicionales pasen a un segundo plano (Social Media Marketing, 2011). Hoy, Snapchat, Instagram, los podcast y los blogs ganan audiencia junto a las posibilidades de cuentas wiki. 
Aun así, persiste el déficit de información respecto a los asuntos sociales y los sucesos en los países en vía de desarrollo. Esta situación mantiene el desinterés generalizado en la población del entonces primer mundo. A pesar de ello, fue un reportaje de Michael Buerk, desde la $\mathrm{BBC}$, el que conmocionó al mundo sobre la gran hambruna que vivían los habitantes de Etiopía.

\section{UN PASO PARA SENSIBILIZAR Y HACER FUNDRAISING}

Artistas como Bob Geldof y Midge Ure, en 1984, deciden unirse musicalmente para conformar Band Aid. Luego componen Do they know it's Christmas, una canción que no solo busca sensibilizar a los habitantes del norte sobre la situación de las poblaciones del Cuerno de África, sino que logra el respaldo de grandes celebridades ${ }^{15}$. No obstante, el objetivo principal, que era recolectar fondos para ayudar en la crisis que vivía el país africano, no se logró (ввС).

$\mathrm{Al}$ año siguiente, 1985, nuevamente el actor Bob Geldof inicia la campaña Live Aid, por medio de la cual se realizaron una serie de conciertos a uno y otro lado del Atlántico (Estadio John F. Kennedy, Estados Unidos y Estadio de Wembley, Inglaterra), conciertos que se convirtieron en un hito, en términos de campañas y movilizaciones que involucraban a gente de distintos lugares del planeta. Su objetivo principal fue recolectar recursos para la lucha contra la hambruna en países de África oriental, específicamente para Etiopía y Somalia. Estos conciertos fueron simultáneos ${ }^{16}$. Si bien la realización de estos dos conciertos contó con la participación de diferentes celebridades como U2, Queen, David Bowie, Madonna y algunos miembros de Los Beatles y The Rolling Stones (El Excelsior, 2015), lo que hay que destacar es que "la música y los músicos fueron secundarios en el evento" (Ullestad, 1987, p. 71). El centro siempre fue la movilización de recursos para erradicar la hambruna. No obstante, el impacto de los mismos motivó a diferentes empresas y políticos para ser parte activa de estos. De hecho, Ronald Reagan, entonces presidente de Estados Unidos (p. 71), quiso involucrarse en la campaña. Luego, se comprometió con el Programa de Asistencia a África, un programa de largo plazo que se adelantó como política de su administración. Más adelante se volverá sobre esta decisión política.

Estos conciertos lograron no solo que los países del Cuerno de África recibieran donaciones por US\$250 millones (Portafolio, 2010), sino que alcanzó una audiencia de 1600 millones de personas en 72 países. Ello permitió generar una gran sensibilización para hacer un alto a la hambruna que para entonces se vivía en algunos países africanos (El Excelsior, 2016). Sin duda, el apoyo de los medios de comunicación que realizaron la transmisión en vivo posibilitó incrementar los donativos. Ya lo había registrado la misma prensa, cuando

15 Entre otras se destacan Bono, Sting, Boy George y George Michael.

16 El 13 de julio de 1985. 
describió el impacto de la interpretación de Héroes, por el cantante David Bowie, en el Estadio de Wembley. Aquí cabe recordar la literatura académica cuando hace referencia al mercado de beneficencia, porque en la mitad del espectáculo le recordó a los asistentes y a los televidentes que se requería recaudar el máximo monto de fondos para erradicar la pobreza y con ella el hambre en África. A la par, los estrategas de Live Aid proyectaron en las pantallas de los estadios las imágenes que evidenciaban la cruda realidad enfrentada por etíopes y los somalí (Corrales, 2015). Por esta razón, Ullestad (1987, p. 71) considera que "Live Aid rompió la realidad del consumidor, en términos de tendencia de ideas y creencias; su cortina de humo para observar lo que sucede al otro lado del mundo" (traducción propia) ${ }^{17}$.

Los fanáticos del rock and roll, muy seguramente, recordarán que además de la canción Do they know it's Christmas se lanzó la campaña USA for Africa que rápidamente se institucionalizó como fundación. Desde el inicio fue una coalición de 45 artistas reconocidos internacionalmente ${ }^{18}$, para sensibilizar sobre el problema de las hambrunas en el continente africano. Para entonces, Michael Jackson y Lionel Richie escribieron la canción We are the world ${ }^{19}$, que junto con Do they know it's Christmas se convirtieron en los himnos del Live Aid.
En 1986, ya institucionalizada como fundación USA for Africa, se sigue trabajando con diferentes repertorios para el mismo propósito: erradicar la pobreza y acabar el hambre. Es por ello que lanzan la campaña Hands Across América, con el objetivo de sensibilizar a los estadounidenses sobre las dificultades que viven los habitantes del continente africano. También buscan recursos a través de donaciones $y$, a la fecha, registran inversiones por US\$ 100 millones en los países africanos donde operan. Según los registros de su página web, entre sus prioridades están la lucha contra la hambruna, el transporte de agua, la educación y el cambio climático (USA for Africa Foundation, 2016).

Como resultado de la presión ejercida por las celebridades, en la década de los ochenta puede anotarse el establecimiento del Programa de Acción para la Recuperación de la Economía y el Desarrollo de África, por parte de las Naciones Unidas, en 1986. Adicional a esto, Estados Unidos respondió a la crisis de dos maneras: en el año fiscal de 1988, el Congreso aprobó una nueva cuenta exclusiva para el continente africano, que sería manejada por la Agencia para el Desarrollo Internacional. Segundo, el involucramiento del presidente Reagan originó el compromiso, a largo plazo, del programa dedicado al crecimiento de África, cuyo objetivo principal era acabar el hambre en el continente (Gladson, 1988).

\footnotetext{
17 "Live Aid served to disrupt the smooth flow of ideas and beliefs because it was also a window onto another part of the world, a window through the haze of the mirage, a view behind the screen of consumer "reality".

18 Como Michael Jackson, Bruce Springsteen, Lionel Richie y Stevie Wonder, Bob Dylan y Ray Charles.

19 La difusión de esta canción logró recolectar alrededor de 60 millones de dólares, los cuales fueron destinados a la ayuda humanitaria (USA for Africa Foundation, 2016).
} 


\section{SE REPITE LA HISTORIA PARA AYUDAR A ÁFRICA}

Sin duda alguna, los eventos y las canciones realizadas en la década de los ochenta serían el impulso para que más celebridades se insertaran en el activismo, tanto para sensibilizar como para recolectar fondos a fin de intentar acabar con los problemas que perjudicaban al continente africano.

La canción Do they know it's Christmas, en tres ocasiones más, volvió a cobrar importancia para recaudar fondos. El primer remix de este sencillo fue en 1989, cuando a los pioneros de esta canción se les unieron artistas como Kylie Minogue y Cliff Richard. Nuevamente, las ganancias de la producción artística y el tiempo de estas celebridades fueron donadas a la causa. El segundo remix se dio en 2004, cuando también resurge Band Aid, para entonces ya conocida como Band Aid 20. En esta ocasión, el vocalista de Coldplay, Chris Martin, junto con Paul McCartney, Bono y George Michael se solidarizan con las personas afectadas por el conflicto en Sudán. La tercera se dio en el año 2014, cuando artistas como One Direction, Sam Smith, Ed Sheeran, Chris Martin y Bono, se unieron para luchar en contra del virus del ébola que cobró muchas vidas en los países de África occidental (El Excelsior, 2016).
Fueron tres plagas de la caja de Pandora que las celebridades quisieron disminuir: la hambruna, el conflicto y el virus (ébola). Con su arte buscaron sensibilizar. En las letras de sus canciones dejaron mensajes para concientizar al resto de la población y, especialmente, a sus seguidores. Se debe actuar. Lo que ya en el siglo Xxi se conoce como la responsabilización de los diferentes agentes, que en algunos temas se entiende como la corresponsabilidad ${ }^{20}$.

Es en este periodo cuando la revista Times reconoce el trabajo filantrópico de Paul David Hewson, quien como activista y celebridad líder de causas sociales es conocido como Bono, cantautor de la banda británica U2. Según Richey y Ponte (2008, p. 717),

Bono se involucró como activista político a inicios de los 90, cuando escribió una carta abierta a Tony Blair y estuvo en reunión con líderes mundiales; acciones que tuvieron impacto directo en la cancelación de la deuda que el G-7 ofreció en 1999 y en la contribución de Estados Unidos a la iniciativa de los países altamente endeudados (НІср) (traducción propia) ${ }^{21}$.

El impacto de su accionar permitió que, en 2002, sostuviera una reunión con el entonces presidente de Estados Unidos, George W. Bush, en la cual se anunció el respaldo al Compact for Global Development, aumentando el presupuesto de la ayuda externa a US\$ 5

20 Se refiere a la responsabilidad compartida que tienen dos o más actores.

21 “Bono's engagement in political activism dates at least to the early 1990's. His letters to newspapers, public challenge to Tony Blair and meetings with world leaders are thought to have had a direct impact on the debt cancellations that the G7 offered in 1999 and on the US contribution to the Heavily Indebted Poor Country (HIPC) initiative". 
billones, entre 2004 y 2006 (Richey y Ponte, 2008, p. 717).

Si bien la estrategia en términos de campaña es la misma, lo que vale destacar es que su alcance se expande. Hay más gente involucrada, tanto en términos de la concientización como de la motivación para tomar acción y ayudar a África. Ya no solo en términos generales de pobreza sino que, de manera particular, se entra a trabajar en el mejoramiento de las condiciones de salud, la reducción del conflicto que acelera las condiciones de pobreza, y la hambruna que se vivía. Para ello, se logra el accionar de los Estados, mejorando sus aportes en ayuda oficial al desarrollo y en oferta de cooperación internacional. Hay recursos que le dan soporte a la voluntad política que registran los medios de comunicación por el mundo.

\section{El Live 8 y el Grupo de los Ocho}

En el 2005, dos décadas después del lanzamiento del Live Aid, el cantante y activista político Robert Frederick Zenon, popularmente conocido como Bob Geldof, hace un llamado a los miembros del G-822 para redoblar los esfuerzos y reducir la pobreza.

Apenas corría el primer quinquenio del compromiso de las Naciones Unidas con los Objetivos de Desarrollo del Milenio y con la narrativa central de la pobreza. Era necesario mantener los esfuerzos para hacer de esta un problema del pasado. Entonces, diferentes artistas internacionales decidieron aunar esfuerzos con Make Poverty History ${ }^{23}$, en una serie de 11 conciertos, el 2 de julio del 2005, en varias ciudades del Reino Unido, Francia, Rusia, Italia, Alemania, Sudáfrica, Japón, Canadá y Estados Unidos.

Las celebridades involucradas en el resurgimiento de este evento fueron: el creador del Band Aidy del Live Aid, Bob Geldof, el actor Richard Curtis y el líder de la banda U2, Bono. Estos simultáneos y múltiples conciertos contaron con la presencia de nuevas estrellas del espectáculo como Madonna, Stevie Wonder, Snow Patrol, Coldplay y Robbie Williams (ввс).

En esta oportunidad, la petición de Bob Geldof no solo era para promover los conciertos entre las ocho grandes potencias del momento, sino para que los jefes de Estado tomaran acción, en términos de reducir la deuda de los países africanos, como una manera de reducir la pobreza. Estados Unidos, Gran Bretaña, Alemania, Francia, Italia, Canadá y Japón, para ponerse al día con los aportes para la cooperación internacional al desarrollo con África, debieron duplicar sus aportes de $\$ 25$ mil millones a $\$ 50$ mil millones para el año 2010; de estos aportes, el $50 \%$ del monto iría para el continente de África; también este

22 Nombre asignado al grupo de países con las industrias más grandes del planeta. Está conformado por: Estados Unidos, Canadá, Francia, Italia, Alemania, Reino Unido, Japón y Rusia.

23 Make Poverty History fue una coalición de alrededor de 400 organizaciones benéficas, sindicatos y grupos religiosos, dentro de las que se encontraba Oxfam, Comic Relief y Transport and General Workers Union (BBC). 
grupo de países diseñaría nuevas estrategias para mejorar la salud en el continente (Corrales, 2015).

En este tercer momento, en el que las celebridades juegan un rol importante para concientizar y mover grandes masas para la acción, lo que se destaca es el involucramiento de los líderes políticos y económicos del mundo. Más que narrativa en torno a la pobreza, se logran decisiones de política internacional para el Make Poverty History y, con una gran campaña de lobby internacional, se remarcan hitos icónicos como que el 2005 haya sido declarado el Año de África, por parte del Reino Unido. Mejor aún, que los Estados hubiesen destinado cifras más importantes para la cooperación internacional.

\section{LA CUOTA COLOMBIANA (SHAKIRA Y LOS PIES DESCALZOS) Y LATINA}

Acabar con la pobreza en el mundo es un reto no solo en África. En Latinoamérica, y en el caso específico de Colombia, la tarea aún es larga. La intención no es considerar este caso como exclusivo, simplemente se menciona como una muestra de lo que sucede en el marco territorial de las autoras. Estrellas de la farándula como Shakira Isabel Mebarak Ripoll han hecho marketing social. Con sus acciones enriquecen las alternativas cuando de comunicación para el desarrollo se trata. En 1997, Shakira creó la fundación Pies Descalzos para prestar una educación pública de calidad a los niños colombianos que se encuentran en situación de vulnerabilidad (Fundación Pies Descalzos, s.f.). Desde su conformación, más de 10.000 niños y 67.000 jóvenes se han beneficiado con los servicios ofrecidos en siete colegios de Barranquilla, Soacha, Cartagena y Quibdó.

Shakira parte de la educación de calidad como medio para superar la pobreza. Este trabajo lo adelanta en Colombia y también en Sudáfrica y en Haití. En junio de 2010, cuando el país africano era sede del Campeonato Mundial de Futbol, Pies Descalzos lanzó la campaña Mango-Waka Waka, con el objetivo de recaudar fondos para la construcción de un salón multipropósito para los niños de la escuela de Soweto, al sureste de Johannesburgo, Sudáfrica, la tierra de Nelson Mandela, el líder y expresidente del pueblo sudafricano.

La estrella colombiana del pop también ha trabajado en alianza con grandes marcas; es el caso de Freixenet, la marca de champaña con la que adelantó una pauta publicitaria para recaudar fondos y con ellos construir dos nuevas escuelas en Puerto Príncipe, Haití. Esta fue una promesa que ella se hizo, luego del fuerte terremoto que sufrió la isla (Fundación Pies Descalzos, s.f.).

El altruismo de la colombiana le mereció ser nombrada como Embajadora de Buena Voluntad del Fondo de las Naciones Unidas para la Infancia (Unicef), en 2003. Además de esto, durante la realización del Foro Económico Mundial (World Economic Forum - weF) del 2017, en Davos, Suiza, la artista colombiana fue condecorada con el Crystal Award, un premio que se otorga a las personalidades que sirven como modelos para los líderes de la sociedad, por su trayectoria en la defensa de la educación de la niñez (El Tiempo, 2017).

Así, esta celebridad colombiana le apunta a una dimensión específica de la pobreza: la educación. Que sea de calidad y que sus beneficiarios 
cuenten con todas las condiciones básicas para el pleno disfrute de este derecho. De esta manera, en su momento, ella se articuló con el Objetivo de Desarrollo del Milenio (ODM) 1 que buscaba erradicar la pobreza extrema y el hambre, y el ODM 2 , que hacía referencia a lograr la educación primaria universal. Más tarde, cuando se fijaron los Objetivos de Desarrollo Sostenible (oDs), siguió con los objetivos: Fin de la pobreza (oDs 1), Hambre cero (oDs 2) y Educación de calidad (oDs 4). No es que se realice un trabajo paralelo o diferente a los requerimientos humanitarios, sino que, por el contrario, se trabaja mancomunadamente, con el sector público y con las grandes empresas, para alcanzar los objetivos globales que si bien buscan erradicar la pobreza, hoy giran en torno a eliminar la inequidad.

Aquí se podrían mencionar otros casos colombianos como el del cantautor Juanes, quien trabaja en temas de paz, pero la lista no se extenderá. Entre los latinos cabe mencionar a Ricky Martin ${ }^{24}$, quien trabaja para eliminar la trata de personas, con la Fundación que lleva su nombre; los mexicanos de Maná con la Fundación Ecológica Selva Negraa ${ }^{25}$; como se señaló, estos son algunos referentes de una lista que puede ser extensa.

\section{El líder del Global Citizen}

Otro de los personajes que ha logrado acaparar la atención de multitudes y dar a conocer los problemas que afectan a los países del tercer mundo es el vocalista de la banda Coldplay: Chris Martin. Su activismo abarca la lucha contra la pobreza, la expansión del comercio justo, los derechos humanos, viH-sida, y, de manera especial, el viH-sida en la niñez. No lo ha hecho solo. Es embajador de organizaciones de la sociedad civil como Oxfam, Amnistía Internacional, Make Trade Fair, War Child, MusiCares, Childrens with AIDs, Human Rights First, entre otras (Look to the stars, s.f.).

Desde 2002, Martin está involucrado con Oxfam. Fue en esta organización inglesa donde comenzó su activismo por los temas del comercio justo. Ello lo llevó a visitar Haití, donde compartió con agricultores de café y arroz, y percibió los efectos perversos que ha generado el comercio en países en vías de desarrollo. Precisamente por eso hizo parte activa para el lobby que Oxfam adelantó en la cumbre de la Organización Mundial de Comercio (OMC) en Cancún, México, en 2003. Martin logró línea directa con el entonces director, Supachai Panitchpakdi. El vocalista de Coldplay resaltó la importancia de evaluar las reglas que rigen el comercio ya que estas tienen un efecto perverso y llegan a perjudicar a los más pobres. Diez años después, en 2013, hizo una versión acústica de In my place que fue el tema central de la campaña Grow, de Oxfam (Oxfam, s.f.).

El papel del vocalista dentro de la sensibilización no cesa. Ya tiene compromisos adquiridos para en los próximos años con Global Poverty Project ${ }^{26}$. Una plataforma con más 650

\footnotetext{
24 Ampliar en Ricky Martin Foundation (s.f.).

25 Ampliar en Selva Negra (s.f.). Disponible en http://www.selvanegra.com.mx/

26 Plataforma social creada en 2008.
} 
millones de personas que están comprometidas con la superación de la pobreza extrema ${ }^{27}$, y que tiene como estrategia trabajar con niñas y mujeres en temas como salud, educación, alimentos y hambre, saneamiento básico, medio ambiente y ciudadanía.

Ellos también recurren a las campañas globales con reeditores sociales como Chris Martin y otras estrellas del espectáculo artístico, con las que se realizan eventos para recaudar fondos. La intención inicial es sensibilizar en la búsqueda de un cambio social. Están comprometidos con la agenda 2030, que implica alcanzar los oDs. Hoy por hoy, la labor de los ciudadanos globales ha generado al menos 130 acciones concretas, anuncios oficiales de líderes políticos y recursos por más de US\$ 25,6 millones (Global Citizen, 2017).

Desde 2012, la plataforma ha establecido el festival Global Citizen como el eje de su accionar; primero en el Central Park de Nueva York, y más recientemente con el evento simultáneo en Mumbai, India. En la Gran Manzana, Chris Martin se convirtió en su líder y director creativo (McCarthey, 2015). Cabe anotar que este festival es considerado como uno de los eventos paralelos a la Asamblea General de las Naciones Unidas, y fue diseñado así, justamente para darle mayor visibilidad, y lograr incidir en la agenda internacional. Para presionar con movilización de masas, el Global Citizen ha contado con la colaboración de otras celebridades internacionales como Beyonce,
Jay-Z, Rihanna, Metallica, Pearl Jam, entre otras (cTV News, 2016), quienes atraen sus propios fanáticos. No obstante, lo más importante es la incidencia que se hace en el seno de las Naciones Unidas.

Ya se había notado el logro de la meta establecida para el ODM 1, en 2010, pero la pobreza aún persiste y la situación se agrava con el debilitamiento del Estado de bienestar. Por eso, las celebridades del espectáculo continúan realizando repertorios de acción que contribuyan a su erradicación, en las dimensiones que la abarcan, como en su momento lo señaló Sen, cuando obtuvo el Premio Nobel ${ }^{28}$. En algunas de esas dimensiones ha focalizado su esfuerzo el vocalista de Coldplay, y por eso se ha convertido en ícono del siglo XXI para la erradicación de la pobreza. Su dedicación intensa a trabajar en las dimensiones anotadas, en el campo social y político, muestra a sus seguidores que está comprometido con la transformación que requieren las poblaciones vulnerables. Es más, transmite mensajes de sensibilización en sus canciones y llega a diferentes lugares del planeta con otras celebridades, también apoderadas de la causa. La estrategia de realizar un festival como Global Citizen le permite seguir en la escena.

\section{CONSIDERACIONES FINALES}

A lo largo del tiempo, los éxitos de las diversas campañas lideradas por las celebridades del es-

\footnotetext{
27 Fundada por los activistas humanitarios Hugh Evans, Simon Moss y Wei Soo.

28 Por su contribución al análisis del bienestar económico, en donde abarca diferentes situaciones inherentes al problema de la pobreza.
} 
pectáculo han sido debatidos. En este artículo se mostraron los hitos establecidos por celebridades en su trabajo por erradicar la pobreza, narrativa central de final del siglo xx, y eje para lograr el desarrollo, en el primer quindenio del siglo xxi. El mundo se comprometió primero con los ODM, ahora se han fijado los ODs, y quizá hay más dimensiones, pero el problema es el mismo: hoy se habla de solucionar la inequidad. De una u otra manera, los artistas siguen involucrados, acuden a sus audiencias para sensibilizarlos y llevarlos a la acción. Hay que hacer algo y está en las manos de cada uno. Donar es la primera acción inmediata, entonces las celebridades invitan a donar para recaudar fondos que permitan acabar con las causas de ese gran problema de la humanidad.

Las campañas realizadas en uno u otro momento, como cualquiera de las cinco señalas a lo largo de este escrito, son vistas desde diferentes aristas. Algunos observan un lado oculto, como es el caso de Harrison (2010, p. 393), quien considera que las campañas que se han realizado en torno a la difícil situación que ha atravesado el continente africano han estado alejadas de los africanos, y que simplemente se ha usado a África como ejemplo para que los gobiernos aparezcan responsables frente a situaciones críticas en el mundo y se conviertan en un ejemplo de moral. Un oportunismo cínico. Los argumentos morales del accionar han estado ligados a situaciones generales sin tocar temas específicos. No obstante, lo que se advierte al revisar cada uno de los casos es que así como la narrativa de la pobreza cambia, las focalizaciones de la estrategia de campaña también se especializan.
De la misma manera, los críticos de este repertorio de acción señalan que la concientización de las personas es superficial. Harrison (2010, p. 395), por ejemplo, anota que las campañas dirigidas a mostrar la pobreza son muy vagas y no muestran las causas ni los efectos devastadores de las políticas aplicadas por el G-8.

A pesar de las críticas que se han generado a raíz de estas campañas, no se puede negar que el proceso de "africanización" ha servido para que en el resto del mundo se tenga el imaginario sobre la pobreza. Con todos los efectos que se puedan sumar, es innegable la cantidad de gente que se ha sido movilizada por las celebridades. También debe considerarse a la multitud que en diferentes partes del mundo ha estado comprometida y se comprometerá con las campañas lideradas por las estrellas del espectáculo.

Desde que se comenzó a abordar la pobreza en el mundo, la academia ha ido especificando las dimensiones, y los líderes políticos, económicos y sociales se han involucrado. Puede ser en mayor o en menor grado, pero el tema está en la agenda de política internacional y en ello, sin lugar a dudas, las celebridades han jugado un papel que poco se ha estudiado en las relaciones internacionales. Como componente de la sociedad civil global tiende a ser excluido y, simplemente, es reseñado más como análisis de marketing que como agente en la arena internacional. De esta manera, los estudios académicos (Ullestad, 1987; Richey y Ponte 2008 y Harrison 2010) se centran en la estrategia comunicativa que desarrollan las celebridades y tiende a perderse la dimensión internacional. 
Desde las relaciones internacionales puede anotarse que, siendo la pobreza un problema global, hay líderes sociales y políticos, o, mejor aún, liderazgos o como lo mencionamos anteriormente, reeditores sociales que desde las organizaciones de la sociedad civil global o internacional buscan una transformación de la situación. Según el contexto trabajan con otros agentes y para ello realizan lobby en los escenarios internacionales en aras incidir en las decisiones de política internacional, pero también trabajan con las bases concientizando sobre las problemáticas y llevando a la acción solidaria para buscar el altruismo que permita la transformación deseada. Ya se vio en el caso de Geldof, Paul McCartney, Bono, George Michael, Madonna, Robbie Williams, Shakira y Chris Martin, quienes han ido focalizando sus campañas según el cambio de narrativa en términos de pobreza. Ejemplo de esto son los casos analizados de Shakira con su trabajo enfocado en la educación, y el de Chris Martin y su lucha por un comercio justo. Cada una de estas celebridades ha tenido acceso al poder.

Aun con un abordaje específico, en este artículo queda demostrado que las celebridades trabajan en un contexto global que está comprometido con los objetivos que la humanidad ha considerado como básicos para transformar los problemas que actualmente afrontan los países en vía de desarrollo. Eso es lo que hoy en día conocemos como los oDs.

Es claro que los artistas tienen audiencias cautivas y en ellas difunden sus mensajes para sensibilizar sobre la pobreza, estrategia que es eficaz para recolectar fondos. También se debe reconocer el papel de los medios de comunicación como aliados infalibles de las estrellas del espectáculo. Es una diada que posibilita mayor éxito en términos de difusión de mensajes, pero no necesariamente de información y concientización. Quizá lo importante es que la estrategia posibilita empoderar aún más a los líderes, alcanzar escenarios internacionales, y llevar la voz para que el tema entre en la agenda mundial.

Finalmente, y por el énfasis en el agente sociedad civil global que se ha subrayado en este artículo, se destaca una coincidencia en el boom que para la década de los ochenta tuvieron algunos componentes de esta. Las organizaciones no gubernamentales, las redes transnacionales y los movimientos sociales se robustecieron, aumentaron su prestigio y desarrollaron enfoques novedosos de trabajo. Sin duda, los megaeventos o conciertos simultáneos, en uno y en otro lado del Atlántico, fueron parte de esa novedad y posibilitaron involucrar a un público más amplio. Con ello se logró la presión social necesaria para que organismos internacionales como la Organización para la Cooperación y el Desarrollo Económicos (OCDE) tomarán dos decisiones importantes: una, poner la lucha contra la pobreza como objetivo principal de la cooperación ${ }^{29}$. La otra, la decisión de incrementar la ayuda oficial al desarrollo (AOD). En realidad, en 1985 y en 2005 puede observarse un ligero

\footnotetext{
29 Como consta en "Dando forma al siglo xxi. La contribución de la cooperación al desarrollo", informe de 1996.
} Ampliar en https://www.oecd.org/dac/2508761.pdf 
repunte de esta, en términos absolutos, pero también se observa una disminución en términos del porcentaje del piB de los donantes. Por esta razón, los recursos logrados a través de las campañas por ellos adelantadas eran más que necesarios.

\section{REFERENCIAS}

Banco Mundial (2013). Datos Pobreza: Banco Mundial. Recuperado de http://datos.bancomundial.org/ tema/pobreza

Banco Mundial (2015). Pobreza: Panorama general. Banco Mundial. Recuperado de http://beta.bancomundial.org/es/topic/poverty/overview

ввC (s.f.). Live Aid 1985: How it all happend. BBC UK. Recuperado de http://www.bbc.co.uk/music/ thelive8event/liveaid/history.shtml

ввC (s.f.). WHY LIVE 8?: What is Make Poverty History? $B B C$.

Brady, D. (2005). The Welfare State and Relative Poverty in Rich Western Democracies, 1967-1997. Social Forces, 83(4), 1329-1364. Recuperado de http:// basesbiblioteca.uexternado.edu.co:2072/stable/ pdf/3598396.pdf

Cepal (2010). El progreso de América Latina y el Caribe hacia los Objetivos de Desarrollo del Milenio: desafio para lograrlos con igualdad. Nueva York: CePAL. Recuperado de http://repositorio.cepal.org/bitstream/handle/11362/2977/S2010622_es.pdf;jse ssionid=03EB907B84F177F196DADB9FDEC 45C54? sequence $=1$

Cooper, A. (2008). Celebrity Diplomacy. Boulder: Paradigm Publishers.

Corrales, G. (2015). Live Aid - Live 8: África sigue hambrienta, mas no moribunda. La Nación. Recuperado de http://www.nacion.com/ocio/
musica/Live-Aid-Africa-hambrienta-moribunda_0_1496450344.html

CTV News (2016). Entretenimiento: CTV News. Recuperado de http://www.ctvnews.ca/entertainment/ coldplay-to-play-india-as-anti-poverty-concertexpands-1.3067879

Domínguez Martín, R. (2014). Perspectivas de la cooperación internacional y el desarrollo sostenible después de 2015. Revista Internacional de Cooperación y Desarrollo, 1 (2). Recuperado de http:// www.ciberoamericana.com/pdf/PB.pdf

El Excelsior (2015). 'Live Aid', a 30 años del más ambicioso festival de rock. El Excelsior. Recuperado de http://www.excelsior.com.mx/funcion/2015/07/13/1034312

El Excelsior (2016). A 31 años de que Queen cambió la historia del rock en 'Live Aid'. El Excelsior. Recuperado de http://www.excelsior.com.mx/ funcion/2016/07/12/1104418

El Excelsior (2016). Band Aid, cuando el espíritu navideño se apoderó del rock. El Excelsior. Recuperado de http://www.excelsior.com.mx/funcion/2016/12/21/1135588

El Tiempo (2017). 'La paz va más allá de cualquier papel que se firme': Shakira. El Tiempo. Recuperado de http://www.eltiempo.com/estilo-de-vida/gente/ shakira-recibe-premio-en-el-foro-economicomundial/16793882

Fundación Pies Descalzos (s.f.). Quienes somos: Fundación Pies Descalzos. Recuperado de http://www. fundacionpiesdescalzos.com/es/quienes-somos

Fundación Pies Descalzos (s.f.). Historia: Fundación Pies Descalzos. Recuperado de http://www.fundacionpiesdescalzos.com/es/quienes-somos/historia

Ganz, M. (2011). Public narrative, collective action, and power. In Accountability through public opinion: From inertia to public action (pp. 273-289). 
Recuperado de http://siteresources.worldbank. org/EXTGOVACC/Resources/Accountabilitybookweb.pdf

Gladson, C. (1988). Western Aid to Africa. Issue: A Journal of Opinion, 16 (2), 19-23.

Global Citizen (2017). About us: Global Citizen. Recuperado de https://www.globalcitizen.org/en/ about/who-we-are/

Gumucio Dagron, A. (2004). El cuarto mosquetero: la comunicación para el cambio social. Investigación $y$ desarrollo, 12 (1), 2-23. Recuperado de http:// www.redalyc.org/html/268/26800101/

Harrison, G. (2010). The Africanization of Poverty: A retrospective on "Make Poverty History". African Affairs, 109 (436), 391-408. Recuperado de http://basesbiblioteca.uexternado.edu.co:2072/ stable/40783708

Keck, M. y Sikkink, K. (2000). Activistas sin frontera. México: Siglo Xx.

Look to the stars (s.f.). Celebrities: Look to the stars: the world of celebrity giving. Recuperado de https:// www.looktothestars.org/celebrity/chris-martin

Marín, M. (2009). Movilización social: una apuesta en el mundo de la vida. Comunicación y Ciudadanía (2). Recuperado de http://revistas. uexternado.edu.co/index.php/comciu/article/ view/1837/1643

Marsh, D. (1985). The First Rock \& Roll Confidential Report. Pantheon.

Massal, J. (2007). Sociedad civil internacional: un poder global? Análisis Político (61), 54-72.

McCarthey, J. (2015). Girls and Women: Global Citizen. Recuperado de https://www.globalcitizen.org/ en/content/girls-in-poverty-look-how-coldplayshines-for-you/
OCDE (2011). Perspectives on Global Development 2012. Social Cohesion in a Shifting World. Paris: OECD Development Centre.

OPHI (s.f.) Policy - A multidimensional approach. Recuperado de http://www.ophi.org.uk/policy/ multidimensional-poverty-index/

Oxfam (s.f.). Ambassadors: Coldplay Oxfam. Recuperado de https://www.oxfam.org/en/ambassadors/ coldplay

Policy - A multidimensional approach. Recuperado de http://www.ophi.org.uk/policy/multidimensional-poverty-index/

Portafolio (2010). El concierto Live Aid cumple un cuarto de siglo. Portafolio. Recuperado de http:// www.portafolio.co/economia/finanzas/conciertolive-aid-cumple-cuarto-siglo-431074

Richey, L. y Ponte, S. (2008). Better (Red) ${ }^{\mathrm{Tm}}$ than Dead? Celebrities, Consumption and International Aid. Third World Quarterly, 29 (4), 711-729. Recuperado de http://basesbiblioteca.uexternado.edu. co:2072/stable/20455068

Ricky Martin Foundation (s.f). Home. Recuperado de http://rickymartinfoundation.org/es/

Sampedro, V., Jerez Novara, A. y Lopéz Rey, J. (2002). ONG, medios de comunicación y visibilidad pública. La ciudadanía ante la mediatización de los mensajes sociales. In Revilla Blanco, M., Serrano Oñate, M., Carmona Maya, S., Díez Rodríguez, Á., Teijo García, C., A. Jerez Novara, et al. (ed.). Las ONG y la politica (pp. 251-285). España: Ediciones Itsmo.

Selva Negra (s.f.). Home. Recuperado de http://www. selvanegra.com.mx/

Sen, A. (1999). Desarrollo y libertad. Bogotá: Editorial Planeta.

Social Media Marketing (2011). Breve historia de las redes sociales. Recuperado de https://www.mar- 
ketingdirecto.com/digital-general/social-mediamarketing/breve-historia-de-las-redes-sociales

Ullestad, N. (1987). Rock and rebellion: Subversive effects of Live Aid and 'Sun city'. Popular Music, 6 (1), 67-76. Recuperado de http://basesbiblioteca. uexternado.edu.co:2072/stable/853166
USA for Africa Foundation (2016). About us: USA for Africa Foundation. Recuperado de http://usaforafrica. org/we-are-the-world/

USA for Africa Foundation (2016). Impact: USA for Africa Foundation. Recuperado de http://usaforafrica. org/impact/ 